\title{
Evaluation and analysis of traffic noise level in Kaunas city
}

\author{
Auksė Miškinytè, Audrius Dèdelè \\ Department of Environmental Sciences, Vytautas Magnus University, Vileikos g. 8, Kaunas, LT-44404, Lithuania
}

\begin{abstract}
Environmental noise management is an important part of the policy across the European Union policy context, because transportation and industrial noise is a significant local environmental problem for most of the urban population. Increasing number of vehicles is associated with growing noise level from road transport in urban areas and rising public health problems. Motor transport is considered to be a main source of noise pollution, so it is important to investigate the level of traffic noise and to assess the relationship with traffic flows. The aim of this study was to identify and evaluate noise level from road traffic and to compare noise level near the streets with quiet areas such as parks in Kaunas city. The measurements of traffic flow intensity and noise level were conducted in 40 selected sites near the main streets and in 9 parks in Kaunas city in 2013. In order to measure the noise level, sound level meter, which complies with the latest international standard was used. The study results showed that the highest noise level was measured in near streets with high traffic flow $71.0 \mathrm{~dB}(\mathrm{~A})$. The noise level was $12.3 \%$ and $4.9 \%$ lower in measurement sites near low and medium traffic flow than in sites near high traffic flow intensity, respectively. Correlation coefficient between measured traffic flow intensity and noise level was significantly strong $(\mathrm{r}=$ $0.7344 ; p<0.001)$. The average equivalent noise level in 9 Kaunas city parks ranged from $37.8 \mathrm{~dB}(\mathrm{~A})$ to $53.6 \mathrm{~dB}(\mathrm{~A})$. The average noise level in street and park measurement sites was $68.2 \mathrm{~dB}(\mathrm{~A})$ and $47.3 \mathrm{~dB}(\mathrm{~A})$, respectively.
\end{abstract}

Keywords: Environmental noise level; transport noise; vehicle; traffic flow.

\begin{tabular}{|ll|}
\hline Nomenclature \\
LAeq & equivalent continuous A-weighted sound pressure level written as $\mathrm{dB}(\mathrm{A})$ \\
Lden & $\begin{array}{l}\text { Day-evening-night level based on energy equivalent noise level (Leq) over a whole day with a penalty of } \\
10 \mathrm{~dB}(\mathrm{~A}) \text { for night time noise and an additional penalty of } 5 \mathrm{~dB}(\mathrm{~A}) \text { for evening noise }\end{array}$ \\
$\mathrm{r}$ & $\begin{array}{l}\text { correlation coefficient } \\
\mathrm{p}\end{array}$ \\
\hline
\end{tabular}

\section{Introduction}

Environmental noise pollution is a significant problem in many European countries and in the whole world, which adversely affects the quality of people's lives [1-2]. It's a local problem of modern living, which relates to elevated and disturbing sound levels beyond the comfort levels and impacts on health effects of millions of people in many different levels [3].

The assessment and management of environmental noise is an important part of European Union policy regulated by the Environmental Noise Directive (2002/49/EC) [4]. The priority of EU's environmental noise policy is to improve the implementation of instruments and actions against noise pollution in order to identify noise pollution sources, to reduce its levels and to avoid or prevent the harmful health effects.

The noise sources that affect cities environment are mobile (vehicular traffic, trains, aircraft), stationary (machinery or mechanical equipment, manufacturing facilities etc.), construction (comprise both mobile and stationary sources) and some recreational activities (sports like motorcycling, leisure noise) [5]. The most of the urban population are exposed to environmental noise from traffic sources, accounting for about $80 \%$ of total noise pollution in urban areas [6]. Increasing number of vehicles is associated with growing noise level from road transport. Therefore, motor transport is considered to be one of the main sources of noise pollution, because of its increasing volume and small distance between transport infrastructure and living areas [7-8].

Corresponding author: Auksė Miškinytė. E-mail address: a.miskinyte@gmf.vdu.lt

http://dx.doi.org/10.3846/enviro.2014.036

(C) 2014 The Authors. Published by VGTU Press. This is an open-access article distributed under the terms of the Creative Commons Attribution License, which permits unrestricted use, distribution, and reproduction in any medium, provided the original author and source are credited. 
Road transport is one of the most important environmental polluter in Europe as well as in Lithuania and other countries, though more attention is paid to air quality problems than to noise pollution [9]. More than $40 \%$ of the EU population is regularly exposed to road traffic noise with an equivalent sound pressure level (Leq) over $55 \mathrm{~dB}(\mathrm{~A}), 20 \%$ is exposed to levels exceeding $65 \mathrm{~dB}(\mathrm{~A})$ during the daytime and over $30 \%$ is exposed to levels exceeding $55 \mathrm{~dB}(\mathrm{~A})$ at night, such noise levels can be related to increased risk of health outcomes, especially in some population groups, which are more vulnerable to noise exposure $[3,10]$.

The engine noise and the interaction between vehicle tires and the road surface are two major sources of road transport noise [11]. At low speed the engine noise is dominant, but when the speed is ranging from moderate to high tire-pavement interaction process predominates [12].

The main factors affecting road traffic noise are traffic flow characteristics - traffic volume and density, speed, travel time and the composition of vehicle fleet, also it is important to notice the driving patterns (acceleration and braking) [1314]. Approximately, $20 \%$ reduction in traffic volume can reduce $1 \mathrm{~dB}$ in noise (LAeq), while $50 \%$ reduction in traffic volume can decrease $3 \mathrm{~dB}$ in noise level [15]. The relationship between traffic noise and speed mostly is related with light vehicles, because they account for most of the road traffic and their speeds are higher. The speed limit reduction from $60 \mathrm{~km} / \mathrm{h}$ to $50 \mathrm{~km} / \mathrm{h}$ was predicted to reduce noise level by $2.3 \mathrm{~dB}$ for light vehicles and $1.7 \mathrm{~dB}$ for heavy vehicles.

Epidemiology studies have reported that traffic noise is associated with many adverse health effects. There is evidence that noise exposure can lead to disturbance of sleep, annoyance and stress [16-17]. These health effects can affect human blood pressure and production of certain hormones and in a long period of exposure may increase the risk of hypertension, hearing loss, cardiovascular diseases and mental illness [18-22].

The aim of this study was to identify and evaluate the noise level from road traffic in selected measurement sites in Kaunas city in order to determine the relation between the noise level and traffic flow intensity and to compare the noise level between measurement sites near streets and in city parks.

\section{Material and methods}

The study was conducted in Kaunas city, which is crossed by a number of major highways.

The measurements of traffic flow intensity and noise level were carried out in 40 selected sites close to the main streets and lower traffic intensity streets of Kaunas city in 2013 in order to objectively represent the noise pollution level in various locations of the city. The measurement sites near streets were classified according to traffic flow intensity, ranging from low $(<3000$ vehicles per day), medium (3000-10000 vehicles per day) and high ( $>10000$ vehicles per day) to evaluate the relationship between traffic flow intensity and urban noise level.

The measurements of noise level were also carried out in the main city parks in order to compare the measured noise level between parks and near the streets. The measurement sites and number of points assessed in each park were chosen based on each park characteristics to ensure an adequate noise level; however, most of the measurements were made at the beginning and in the middle of the park. In this study was also evaluated the distance between each park and the nearest main street. The measurements of traffic flow data in each of the street were also taken. The noise level was measured in 20 sites in 9 city parks.

Bruel \& Kjaer sound level meter, which complies with the latest international standards, was used to measure the noise level (Fig. 1). The measurements were carried out in accordance with the Lithuanian Hygiene Norm HN 33-1:2003 the general requirements for the acoustic noise measurement techniques and ISO 1996/1 general requirements.

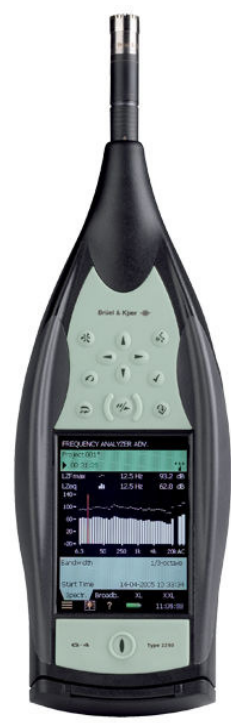

Fig. 1. Bruel \& Kjaer Sound Level Meter - Type 2250 
The possibility of measurements is depended on meteorological conditions and they aren't available in the rain, snow, fog or when wind speed is greater than $5 \mathrm{~m} / \mathrm{sec}$. The microphone was covered with special screen when wind speed was $5 \mathrm{~m} / \mathrm{sec}$. Noise level was measured $1.5 \mathrm{~m}$ above the ground and at least 1-2 $\mathrm{m}$ away from the building facade. The microphone was pointed directly at its target sound source. The duration of measurements was 30-60 minutes in each site on weekdays between 10.00 a.m. and 4.00 p.m. to avoid peak hour traffic.

The traffic volume was estimated by directly counting the number of light and heavy duty vehicles from 10.00 a.m. to 4.00 p.m. on weekdays at selected points in Kaunas city. Traffic flow measurement data were used to calculate vehicle count per day.

Noise level measurement sites are presented in Fig. 2. Kaunas city map with selected street and park measurement sites was made using ArcGIS software (10 version). Geographical Information System (GIS) was used to combine the data layers shown in the map. Most measurement points are distributed around the centre of the city, where the highest population density and building. Data analysis software system STATISTICA 8.0 version was used for statistical analysis of data and assessment of the relationship between traffic flows, the distance to the main streets and noise level. Statistical significance level was evaluated by using $\mathrm{P}$ value $(<0.05)$.

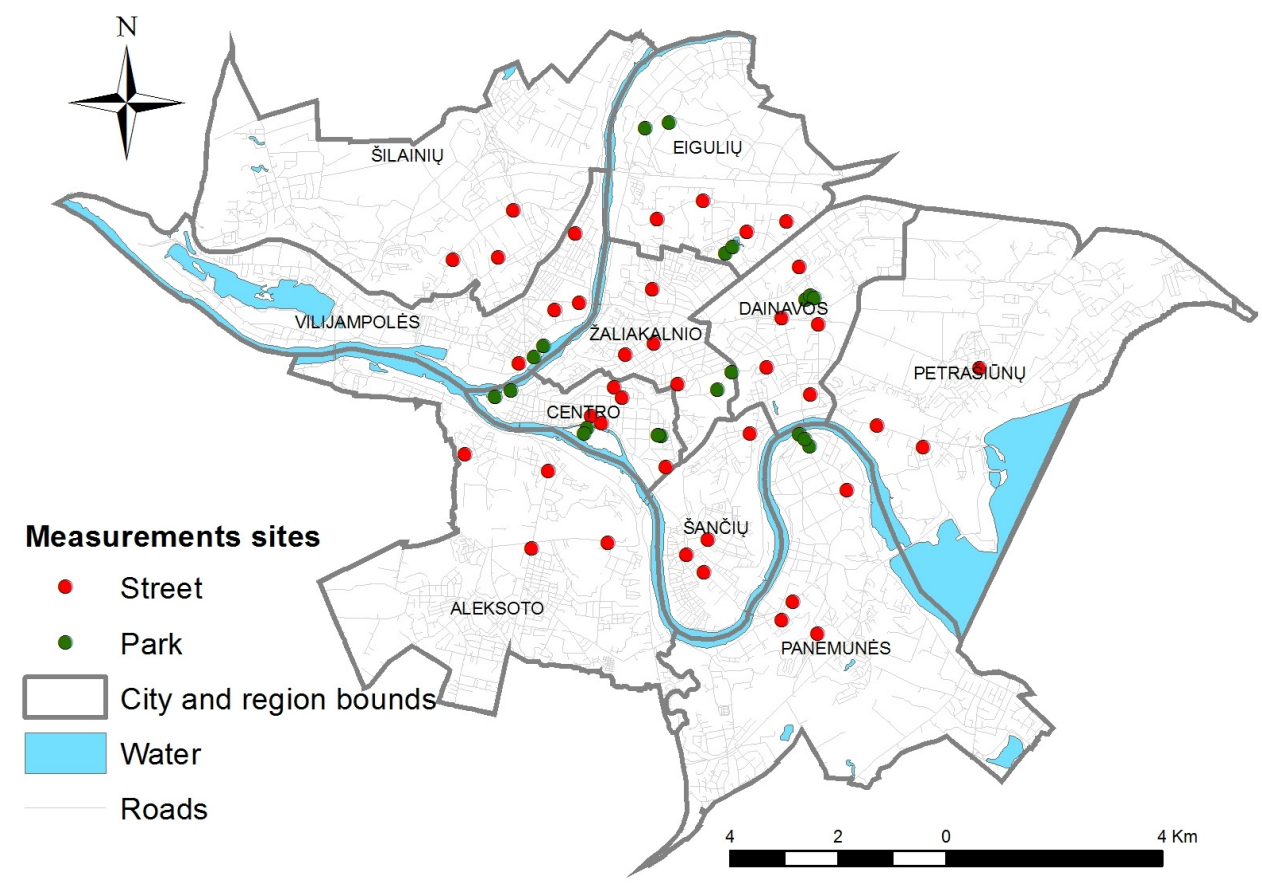

Fig. 2. Noise level measurement sites in Kaunas City

\section{Results and discussion}

Noise level dependence on traffic flow intensity is presented in Fig. 3. It can be seen that it's strong relation between measured traffic flow intensity and noise level. The highest noise level was measured close to streets, where traffic flow intensity was the highest (more than 10000 vehicles per day) and the average equivalent noise level in these measurement sites was $71.0 \mathrm{~dB}$ (LAeq). The measurement sites near Savanorių, Varnių, Veiverių streets, where vehicles count per day was more than 21000, had the highest noise level, ranging from $73.5 \mathrm{~dB}(\mathrm{~A})$ to $74.6 \mathrm{~dB}(\mathrm{~A})$. Measured noise level near streets with low ( $<3000$ vehicles per day) and medium (3000-10000 vehicles per day) traffic flow was lower, respectively $61.4 \mathrm{~dB}(\mathrm{~A})$ and $66.6 \mathrm{~dB}(\mathrm{~A})$. These measurement sites were located further away from the city centre and the lowest equivalent measured noise level was $56.0 \mathrm{~dB}(\mathrm{~A})$. The differences between the highest and the lowest measured equivalent noise level in street measurement sites was $24.9 \%$, while the difference between measurement sites classified by traffic flow intensity into three categories was $12.3 \%$ and $4.9 \%$ lower in measurement sites with low and medium traffic flow comparing with sites near high traffic flow. 


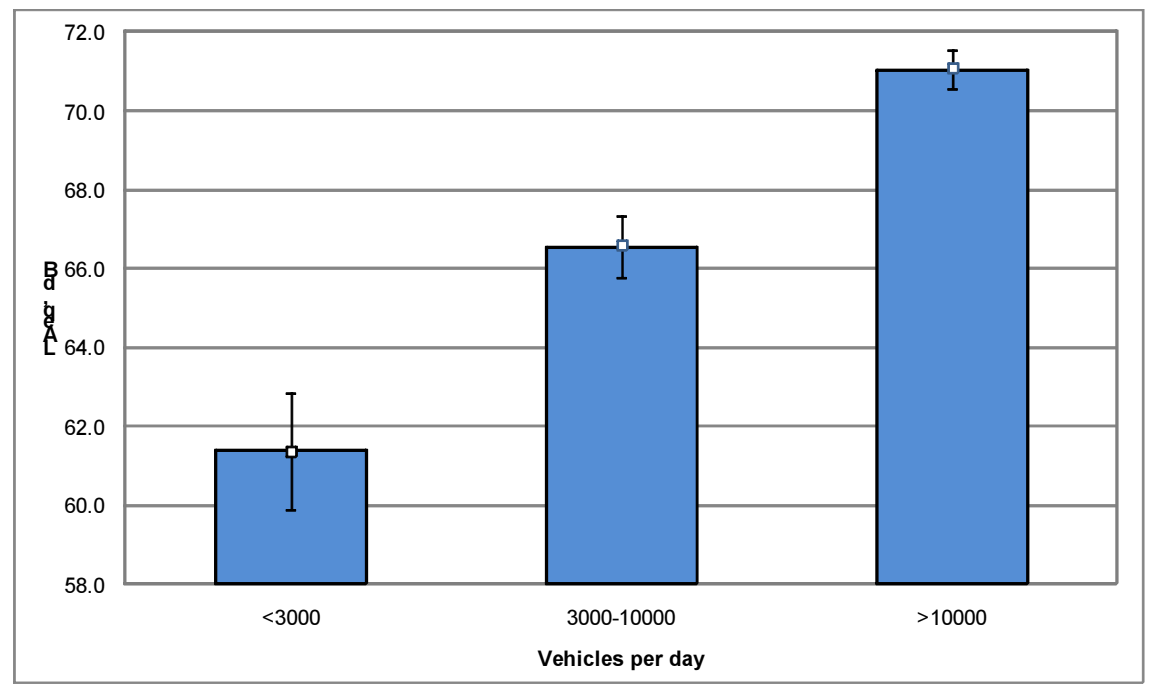

Fig. 3. Noise level dependence on traffic flow intensity

The results of our study showed that traffic flow intensity is the primary environmental noise source having correlation with noise level in street measurement sites. Correlation coefficient was calculated to describe the relationship between measured traffic flow intensity and noise level in 40 measurement sites in Kaunas city (Fig. 4). Significantly high value of correlation coefficient indicated a strong positive linear relationship between two variables such that as values of vehicles count per day increases, values of noise level also increase $(r=0.7344 ; p<0.001)$. Linear regression analysis on the relationship between measured noise level and number of vehicles per day revealed that $54 \%$ of the total variation of noise level can be explained by the regression equation. Noise emissions near the main city streets show that noise level increases with increasing traffic flow intensity. Most of the population exposed to unwanted noise level lives closer to the main streets. According to the last year data of the Statistics Department, $86.76 \%$ of all types of road vehicles accounted for passenger cars and 547 number of personal cars per 1000 population in Kaunas city and these numbers appear to be growing each year, so road traffic flow intensity in the streets of Kaunas city has been increasing over the last year. Thus, the traffic volume and noise level are closely related, especially in urban areas, and most likely that noise pollution will remain as one of the most important environmental problems in the future.

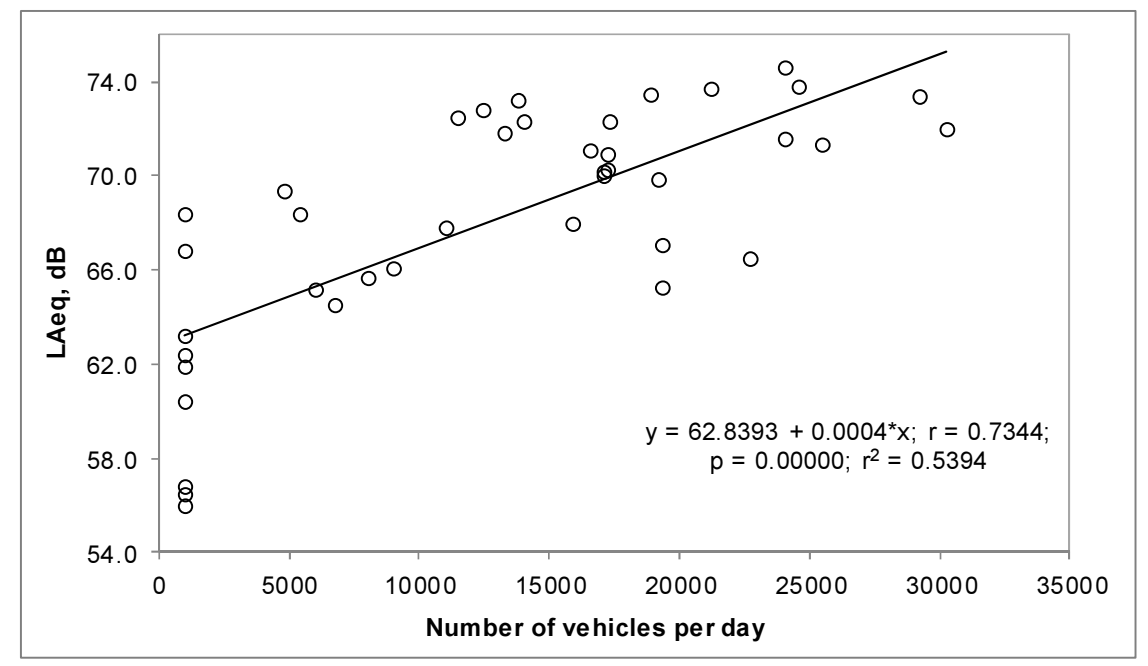

Fig. 4. Relationship between noise level and number of vehicles per day

In this study was also assessed the noise level in quiet urban areas such as the city parks, which is shown in Fig. 5. The average equivalent noise level in 9 city parks ranged from $37.8 \mathrm{~dB}(\mathrm{~A})$ to $53.6 \mathrm{~dB}(\mathrm{~A})$. The lowest noise level was measured in Panemunès Šilas park and the highest noise level was obtained in Ramybès park. Analysis of the results revealed that there is a large influence of vehicle traffic in surroundings of the parks and it's affecting most the noise pollution in the environment of parks. The lowest noise level in Panemunès šilas park can be explained by the distance to the main street, which is 560 meters and medium traffic flow intensity in this street (5424 vehicles per day). Two parks, in which measured noise level was the highest, are in the centre of the city and surrounded by the main streets with intense traffic flow. Ramybès park, where measured noise level was the highest, is located close to the main street with intensive traffic flow, the distance to the street is 190 meters and vehicles count per day is 15888 . To evaluate the relationship between noise level 
in the parks of the city and the distance to the nearest main street the correlation coefficient was calculated. Significantly strong negative linear relation $(r=-0.7507 ; p<0.05)$ was determined, which shows that noise level is much lower in parks distributed further away from the main streets. Our results are similar to the other research studies, which confirmed that parks with low noise level are located away from the downtown area or roads with intensive traffic flow [23-24].

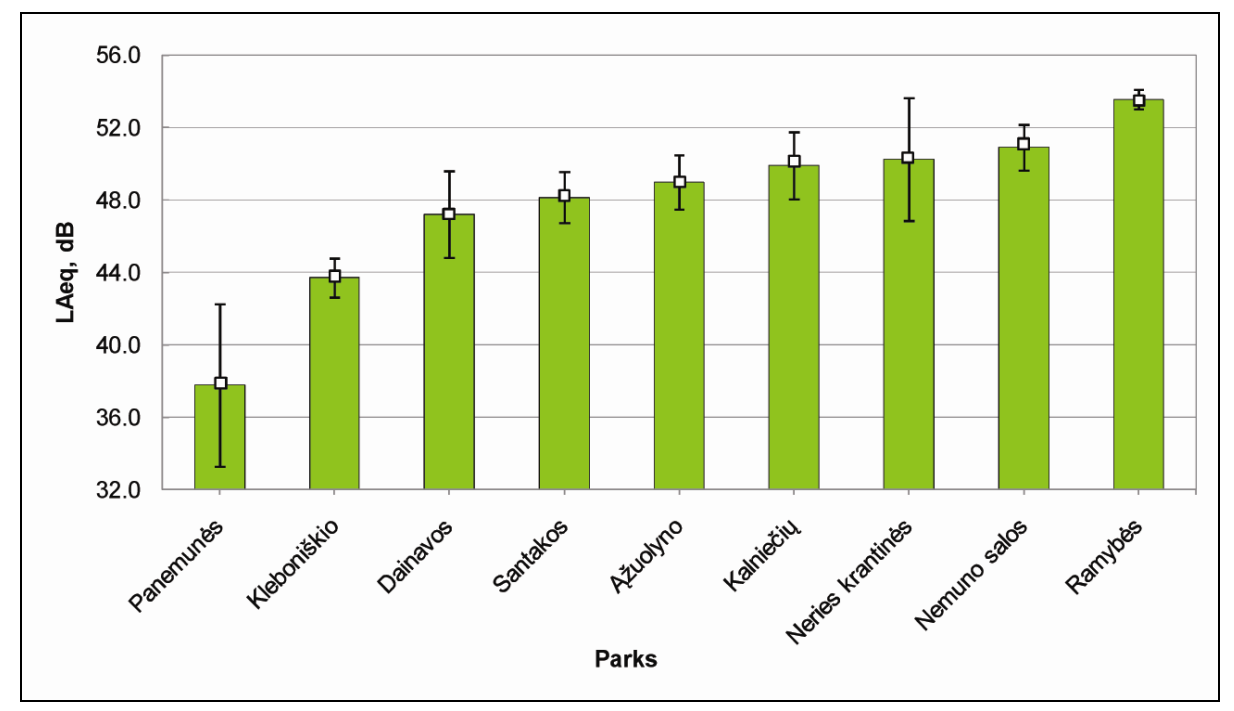

Fig. 5. Noise level in Kaunas city parks

The comparison between measured average equivalent noise level in street and park measurement sites are given in Table 1. The equivalent continuous sound level mean, minimum and maximum value, standard deviation and standard error were calculated for each measurement site. The average noise level in street and park measurement sites was $68.2 \mathrm{~dB}(\mathrm{~A})$ and $47.3 \mathrm{~dB}(\mathrm{~A})$, respectively. The noise pollution in parks was 1.4 times lower than in street measurement sites. The minimum value for street and park measurement sites was $56.0 \mathrm{~dB}(\mathrm{~A})$ and $32.0 \mathrm{~dB}(\mathrm{~A})$, respectively, while the maximum value was 74.6 and 54.8, respectively. The comparable results of noise level range in green areas and city parks have been examined in a few studies $[25,26]$.

Table 1. Comparison of statistics for measured average equivalent noise level $(\mathrm{dB}(\mathrm{A}))$ in street and park measurement sites

\begin{tabular}{llllll}
\hline Measurement site & Mean & Minimum & Maximum & Standard deviation & Standard error \\
\hline Street & 68.2 & 56.0 & 74.6 & 4.95950 & 0.784167 \\
Park & 47.3 & 32.0 & 54.8 & 5.56426 & 1.244206 \\
\hline All groups & 61.2 & 32.0 & 74.6 & 11.17829 & 1.443111 \\
\hline
\end{tabular}

The noise level limits for the residential and public buildings and in their environments are set in the Lithuanian Hygiene Regulation HN 33:2011: Noise limit values in residential and public buildings and in their environment. The equivalent sound level between 6 a.m. and 6 p.m. is $65 \mathrm{~dB}(\mathrm{~A})$, while maximum sound level is $70 \mathrm{~dB}(\mathrm{~A})$. According to these limits, it can be concluded that equivalent noise level measured in sites near streets with medium and high traffic flow was higher and exceeded the Hygiene Regulation (HN 33:2011). For the control and responsibility of noise level and its regulation in residential buildings or districts and also in public places are also responsible separate municipalities. Kaunas city Municipality determines the noise level limits in quiet areas of the city such as parks. The threshold level set at $50 \mathrm{~dB}(\mathrm{~A})$ $\left(\mathrm{L}_{\mathrm{den}}\right)$. Therefore, we can conclude that average equivalent noise level measured in 9 parks of the city is below this limit $(47.3 \mathrm{~dB}(\mathrm{~A})$ ). However, if we analyse the noise level separately in each park, we can see that in two parks (Ramybès and Nemuno salos) measured noise level exceeded the threshold. Urban parks are public open spaces having important environmental functions and attracting residents, so the sound level in these urban areas should be defined as comfortable sound level and natural occurring sounds should be the dominant sound source.

\section{Conclussion}

1. The highest average noise level was in measurement sites near streets with high $(>10000$ vehicles per day) traffic flow $71.0 \mathrm{~dB}(\mathrm{~A})$, while the lowest noise level was measured near streets with low ( $<3000$ vehicles per day) traffic flow, where the average equivalent noise level was $61.4 \mathrm{~dB}(\mathrm{~A})$.

2. The difference between measurement sites classified by traffic flow intensity was $12.3 \%$ and $4.9 \%$ lower in measurement sites with low and medium traffic flow than in sites with high traffic flow.

3. The results of our study showed that traffic flow intensity is the primary environmental noise source having significantly high correlation with noise level in street measurement sites $(r=0.7344 ; \mathrm{p}<0.05)$. 
4. The lowest noise level was measured in Panemunès Šilas park and the highest noise level was obtained in Ramybės park.

5. The average equivalent noise level in street and park measurement sites was $68.2 \mathrm{~dB}(\mathrm{~A})$ and $47.3 \mathrm{~dB}(\mathrm{~A})$, respectively.

\section{References}

[1] Stansfeld, S. A.; Matheson, M. P. 2003. Noise pollution: non-auditory effects on health, British Medical Bulletin 68: $243-257$. http://dx.doi.org/10.1093/bmb/ldg033

[2] WHO. 2011. Burden of disease from environmental noise. Quantification of healthy life years lost in Europe. Copenhagen: World Health Organization Regional Office for Europe. $106 \mathrm{p}$.

[3] den Boer, L. C.; Schroten, A. 2007. Traffic Noise Reduction in Europe - Health effects, social costs and technical and policy options to reduce road and rail traffic noise. Delft, The Netherlands: CE Delft. $70 \mathrm{p}$.

[4] Directive 2002/49/EC of the European Parliament and of the Council "relating to the assessment and management of environmental noise". 2002. Bruxelles.

[5] Jakovljevi, B.; Belojevic, G.; Paunovic K.; Stojanov V. 2006. Road traffic noise and sleep disturbances in an urban population: cross-sectional study, Croatian Medical Journal 47: 125-133

[6] Clark, Ch.; Martin, R.; Alfred T. 2006. Exposure-effect relations between aircraft and road traffic noise exposure at school and reading comprehension, American Journal of Epidemiology 163(1): 27-37. http://dx.doi.org/10.1093/aje/kwj001

[7] Kropp, W.; Kihlman, T.; Forssén, J.; Ivarsson, L. 2007. Reduction potential of road traffic noise - a pilot study. Chalmers University of Technology Alfa Print, Stockholm.

[8] Van Maarseveen, M.; Zuidgeest, M. 2003. Sustainable urban transportation development: A modelling approach, in Urban Transport and the Environmental in the 21st Century. Southampton: Witpress 14: 203-12.

[9] Staatsen, B. A. M.; Nijland, H. A.; van Kempen, E. M. M.; de Hollander, A. E. M.; Franssen, E. A. M.; van Kamp, I. 2004. Assessment of health impacts and policy options in relation to transport-related noise exposures. Topic paper noise. The Netherlands: National Institute for Public Health and the Environment. RIVM report 815120002.

[10] WHO. 2009. Night Noise Guidelines for Europe. Copenhagen: World Health Organization Regional Office for Europe. $185 \mathrm{p}$.

[11] Cho, D. S.; Mun, S. 2008. Study to analyze the effects of vehicles and pavement surface types on noise, Applied Acoustics 69(9): 833-843. http://dx.doi.org/10.1016/j.apacoust.2007.04.006

[12] Mitchell, P. 2009. Speed and Road Traffic Noise. UK Noise Association. 20 p.

[13] Ellebjerg, L. 2008b. The effect of individual traffic flow measures. in Ellebjerg L. ed.

[14] Watts, G.; Nelson, P.; Treleven, C.; Balsom, M. 2005. An examination of vehicle noise test procedures. Wokingham: TRL Limited. TRL PPR044, TRL Ltd. $126 \mathrm{p}$.

[15] Ellebjerg, L. 2008a. Basic traffic - noise relations. in Ellebjerg L. ed.

[16] Hume, K. I.; Brink, M.; Basner, M. 2012. Effects of environmental noise on sleep, Noise Health 14(61): $297-302$. http://dx.doi.org/10.4103/1463-1741.104897

[17] Miedema, H. M.; Oudshoorn, C. G. 2001. Annoyance from transportation noise: relationships with exposure metrics DNL and DENL and their confidence intervals, Environmental Health Perspectives 109: 409-416. http://dx.doi.org/10.1289/ehp.01109409

[18] Babisch, W. 2008. Road traffic noise and cardiovascular risk, Noise Health 10: 27-33. http://dx.doi.org/10.4103/1463-1741.39005

[19] Barregard, L.; Bonde, E., Ohrstrom, E. 2009. Risk of hypertension from exposure to road traffic noise in a population-based sample, Occupational and Environmental Medicine 66: 410-415. http://dx.doi.org/10.1136/oem.2008.042804

[20] Bodin, T.; Albin, M.; Ardö, J.; Stroh, E.; Östergren, P.; Björk, J. 2009. Road traffic noise and hypertension: results from a cross-sectional public health survey in southern Sweden, Environmental Health 8: 1-10. http://dx.doi.org/10.1186/1476-069X-8-38

[21] Riediker, M.; Koren, H. S. 2004. The importance of environmental exposures to physical, mental and social well-being, International Journal of Hygiene and Environmental Health 207: 193-201. http://dx.doi.org/10.1078/1438-4639-00284

[22] Van Kempen, E.; Kruize, H.; Boshuizen, H. C.; Ameling, C. B.; Staatsen, B. A. M.; de Hollander, A. E. M. 2002. The association between noise exposure and blood pressure and ischemic heart disease: a meta-analysis, Environmental Health Perspectives 110(3): $307-317$. http://dx.doi.org/10.1289/ehp.02110307

[23] Szeremeta, B.; Zannin, P. H. T. 2009. Analysis and evaluation of soundscapes in public parks through interviews and measurement of noise, Science of the Total Environment 407: 6143-6149. http://dx.doi.org/10.1016/j.scitotenv.2009.08.039

[24] Zannin, P. H. T.; Ferreira, A. M. C.; Szeremetta, B. 2006. Evaluation of noise pollution in urban parks, Environmental Monitoring and Assessment 118: 423-433. http://dx.doi.org/10.1007/s10661-006-1506-6

[25] Brambilla, G.; Gallo, V. 2013. The perceived quality of soundscape in three urban parks in Rome. Acoustical Society of America. 134(1): 832-839. http://dx.doi.org/10.1121/1.4807811

[26] Nilsson, M. E.; Berglund, B. 2006. Soundscape Quality in Suburban Green Areas and City Parks, Acta Acustica united with Acustica 92(6): 903-911. 